\title{
Allium sativum Extract Chemical Composition, Antioxidant Activity and Antifungal Effect against Meyerozyma guilliermondii and Rhodotorula mucilaginosa Causing Onychomycosis
}

\author{
Marcel Pârvu ${ }^{1, *}\left(\mathbb{0}\right.$, Cătălin A. Moţ ${ }^{2}$, Alina E. Pârvu ${ }^{3}$, Cristina Mircea ${ }^{1}$, Leander Stoeber ${ }^{4}$, \\ Oana Roşca-Casian ${ }^{5}$ and Adrian B. Ţigu ${ }^{1,6}$ (D) \\ 1 Department of Biology, Faculty of Biology and Geology, Babeș-Bolyai University, 42 Republicii Street, \\ 400015 Cluj-Napoca, Romania; mircea.i.cristina@gmail.com (C.M.); adrianbogdantigu@gmail.com (A.B.T.) \\ 2 Department of Chemistry, Faculty of Chemistry and Chemical Engineering, Babes-Bolyai University, \\ 11 Arany Janos Street, 400028 Cluj-Napoca, Romania; augustinmot@chem.ubbcluj.ro \\ 3 Department of Pathophysiology, Faculty of Medicine, Iuliu Haţieganu University of Medicine and Pharmacy, \\ 3 Victor Babeş Street, 400012 Cluj-Napoca, Romania; parvualinaelena@yahoo.com \\ 4 Faculty of Medicine, Iuliu Haţieganu University of Medicine and Pharmacy, 3 Victor Babeş Street, \\ 400012 Cluj-Napoca, Romania; leandrosstoeber@yahoo.de \\ 5 Alexandru-Borza Botanical Garden, Babeș-Bolyai University, 42 Republicii Street, \\ 400015 Cluj-Napoca, Romania; casioana@yahoo.com \\ 6 MEDFUTURE-Research Center for Advanced Medicine, "Iuliu-Hatieganu” University of Medicine \\ and Pharmacy, 23 Marinescu Street, 400337 Cluj-Napoca, Romania \\ * Correspondence: marcel.parvu@ubbcluj.ro
}

Received: 3 October 2019; Accepted: 29 October 2019; Published: 31 October 2019

\begin{abstract}
Onychomycosis is a major health problem due to its chronicity and resistance to therapy. Because some cases associate paronychia, any therapy must target the fungus and the inflammation. Medicinal plants represent an alternative for onychomycosis control. In the present work the antifungal and antioxidant activities of Alium sativum extract against Meyerozyma guilliermondii (Wick.) Kurtzman \& M. Suzuki and Rhodotorula mucilaginosa (A. Jörg.) F.C. Harrison, isolated for the first time from a toenail onychomycosis case, were investigated. The fungal species were confirmed by DNA molecular analysis. A. sativum minimum inhibitory concentration (MIC) and ultrastructural effects were examined. At the MIC concentration $(120 \mathrm{mg} / \mathrm{mL})$ the micrographs indicated severe structural alterations with cell death. The antioxidant properties of the A. sativum extract were evaluated is a rat turpentine oil induced inflammation, and compared to an anti-inflammatory drug, diclofenac, and the main compound from the extract, allicin. A. sativum reduced serum total oxidative status, malondialdehyde and nitric oxide production, and increased total thiols. The effects were comparable to those of allicin and diclofenac. In conclusion, the garlic extract had antifungal effects against M. guilliermondii and R. mucilaginosa, and antioxidant effect in turpentine-induced inflammation. Together, the antifungal and antioxidant activities support that $A$. sativum is a potential alternative treatment in onychomycosis.
\end{abstract}

Keywords: onychomycosis; Allium sativum; antifungal; antioxidant

\section{Introduction}

Onychomycosis is a worldwide common nail fungal infection causing nail white or yellow discoloration, thickening, and separation from the nail bed [1]. Common pathogens in onychomycosis are dermatophytes, non-dermatophyte molds (NDM) and yeasts [2]. The International Society for 
Human and Animal Mycology proposed that the diagnosis of onychomycosis should be replaced by tinea unguium in infections with dermatophyte, by onyxis in infections with yeasts, by ungual candidiasis in infections with Candida, and by ungual mycosis when the infection is a NDM [3]. Tinea unguium are caused mostly by three genera Trichophyton, Microsporum, and Epidermophyton, and fungal infections by Trichophyton rubrum, T. mentagrophytes, and Epidermophyton floccosum are the most frequent worldwide. Among the yeasts Candida species are the most common [2]. Although Candida albicans is still the most frequent yeast pathogen [4], other Candida species such as C. glabrata, C. krusei, C. tropicalis, C. parapsilosis [5], C. guilliermondii [6], etc. are proved to be important pathogens as well [7]. Candida guilliermondii has been isolated from numerous human infections, mostly of cutaneous origin, but it is also found on normal skin, in sea water, animal faeces, wasps, buttermilk, leather, fish, and beer [8]. The species Meyerozyma guilliermondii is most often associated with onychomycosis and candidemia [9].

Onychomycosis is a major health problem because it is so widespread and it is characterized by extreme chronicity and resistance to therapy [10]. For Candida infections treatment difficulties are connected to the relative genetic similarity between Candida and humans, which decreases the number of available targets. Many antifungals used for the treatment of Candida infections target the ergosterol from the fungal plasma membrane. Treatment-resistance of Candida is usually the consequence of ergosterol replacement by a precursor molecule, or a general reduction of the sterol in the plasma membrane.

Other yeasts recently accepted as the causative agents of onychomycosis belong to Rhodotorula genus: Rhodotorula mucilaginosa [11] and $R$. minuta [12]. In vitro susceptibility tests have shown that in onychomycosis the fungus $R$. mucilaginosa is susceptible to low concentrations of 5-flucytosine and amphotericin B, but resistant to high concentrations of terbinafine, voriconazole, itraconazole, and fluconazole [11].

An alternative for onychomycosis control may be the use of medicinal plants due to their richness in bioactive molecules. Among very important medicinal plants are Allium plants which are still intensively studied for their beneficial health effects [13]. Allium sativum is one of the most cultivated plants and it is used as a spice and for its therapeutical properties, such as antifungal effects [14].

Some cases of onychomycosis are associated with paronychia, a periungual inflammation $[15,16]$. Moreover, some studies suggested that low grade systemic inflammation may be associated with onychomycosis as well [17]. The inflammatory response involves an oxidative stress as an injury mechanism [18]. Because reactive oxygen species (ROS) can freely cross intracellular membranes, ROS may induce local and systemic consequences by damaging proteins, lipids, and DNA [19]. Furthermore, untreated onychomycosis could lead to a secondary infection [20]. Considering these facts, oxidative stress should also be considered a secondary target in the therapy of onychomycosis.

The first aim of the study was to evaluate the antifungal effect of $A$. sativum extract against M. guilliermondii (Wick.) Kurtzman \& M. Suzuki and R. mucilaginosa (A. Jörg.) F.C. Harrison causing onychomycosis, by finding the minimal inhibitory concentration (MIC) and using transmission electron microscopy (TEM). A sativum L. (garlic) extract effect on the germination and the in vitro growth of the yeasts was compared to the commercial antifungal naftifine hydrochloride $(10 \mathrm{mg} / \mathrm{mL}$, active substance in Exoderil). The second aim was to evaluate the chemical composition and the antioxidant properties of the A. sativum extract in order to target inflammation associated oxidative stress if paronychia complicates onychomycosis. A phytochemical analysis of the A. sativum extract was also performed.

\section{Results}

\subsection{Phytochemical Analysis of Garlic Extract}

In the analysed garlic extract the concentration of alliin was $1410 \mu \mathrm{g} / \mathrm{g}$ and that of allicin was $380 \mu \mathrm{g} / \mathrm{g}$. Regarding phenolics, only gentisic acid, chlorogenic acid, 4-hydrobenzoic acid, and $p$-coumaric acid were 
found above the limit of quantification (LOQ), but no flavonoid was detected. Further, total phenolic content (TPC) and total tiosulfinate content (TTC) were determined. The data showed that the studied extract contains much more thiosulfinates ( $443 \mu \mathrm{g} / \mathrm{g}$ allicin equivalents) compared with phenolic acids $(15 \mu \mathrm{g} / \mathrm{g}$ gallic acid equivalents) in good agreement with the Principal Component Analysis (PCA) data (see Supplementary Materials: Figures S1 and S2, Tables S1 and S2)

\subsection{Onychomycosis Characteristics}

A clinical case of toenail total dystrophic onychomycosis (Figure 1A) was due to a mixed infection associating M. guilliermondii and R. mucilaginosa was analyzed (Figure 1B).

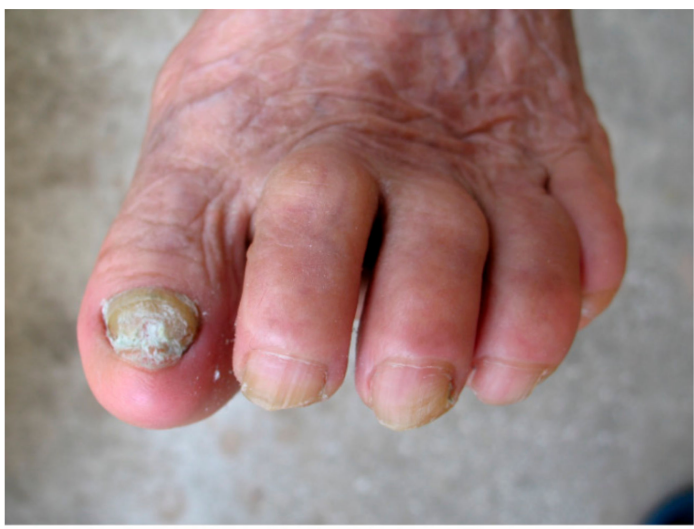

A

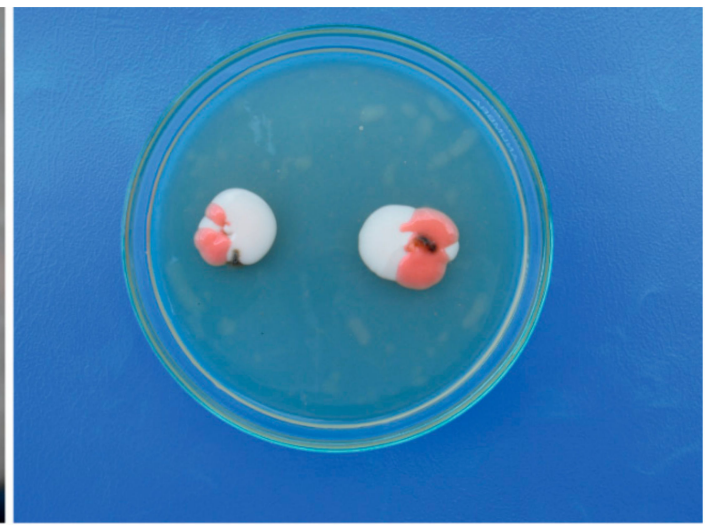

B

Figure 1. (A) Toenails affected by onychomycosis; (B) Colonies of M. guilliermondii (white to cream) and R. mucilaginosa (in red) around a toenail fragment on SDA.

The identification of the fungi M. guilliermondii and R. mucilaginosa was made by the cultural characteristics of the colonies obtained on Sabouraud Dextrose Agar (SDA), the M. guilliermondii colonies being mucoid and white, and the R. mucilaginosa colonies being mucoid and red respectively (Figure 1B). The morphological characteristics of the two species were obtained using scanning electron microscopy (SEM). For M. guilliermondii the SEM micrographs showed spherical to subspherical yeast-like cells, of 2.0-4.0 $\times 3.0-6.5 \mu \mathrm{m}$ in size. Besides these, the fungus had branched and smooth pseudohyphae with dense verticils of blastoconidia (Figure 2A,B). R. mucilaginosa SEM showed only spheroidal to oval budding cells $(2.5-6.5 \times 6.5-14.0 \mu \mathrm{m})$ with carotenoid pigments and without the rudimentary formation of hyphae, and R. mucilaginosa cells were covered by visible mucilage (Figure 2C,D).

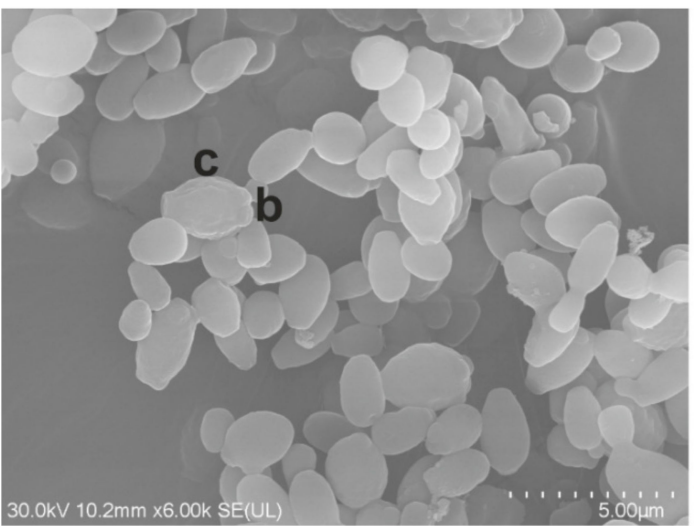

A

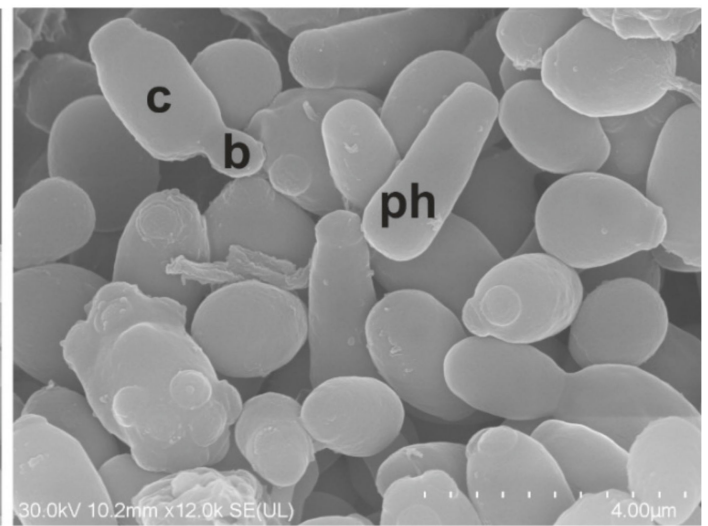

B

Figure 2. Cont. 

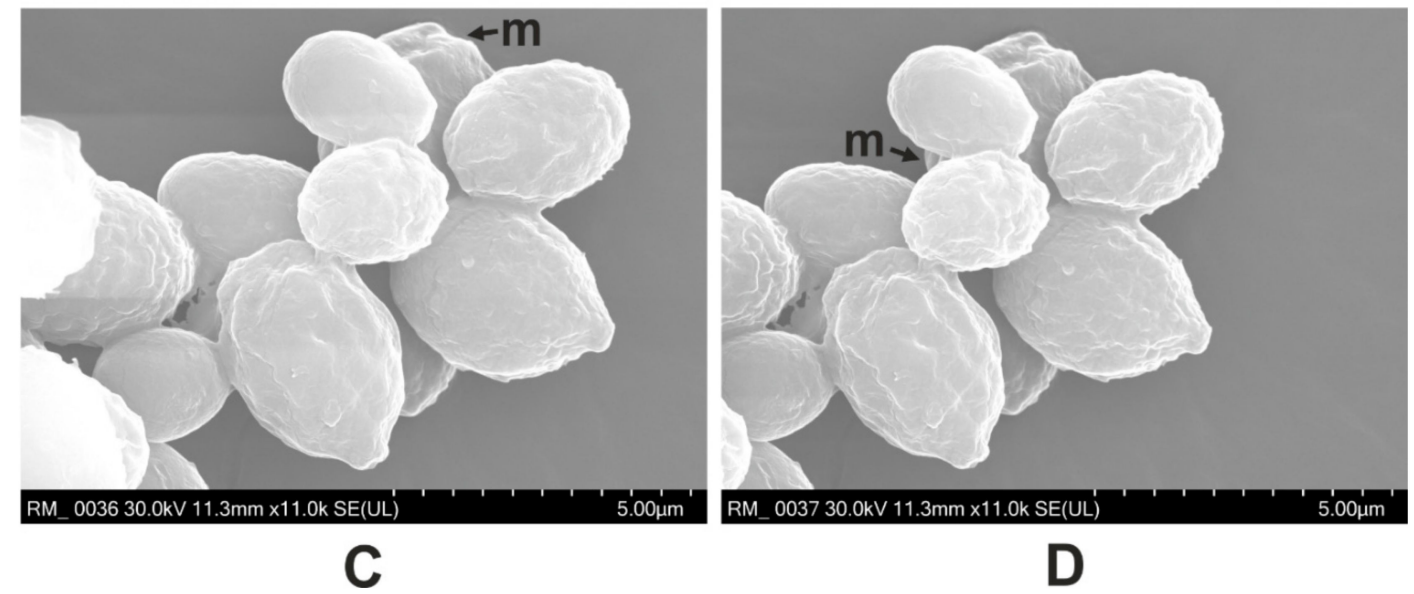

Figure 2. Scanning electron micrographs showing M. guillermondii (A,B) and R. mucilaginosa (C,D). Legend: $b$, bud; c, cell; m, mucilage; ph, pseudohyphae.

\subsection{Molecular Confirmation}

The confirmation of the species was performed by DNA molecular analysis. The obtained DNA sequences were run as queries against the BLAST-NCBI nucleotide database [21] and identically matched M. guilliermondii (Wick.) Kurtzman \& M. Suzuki (GeneBank: MN273503) which is the synonym for Candida guilliermondii (Castell.) Langeron \& Guerra, and R. mucilaginosa (A. Jörg.) F.C. Harrison (GenBank: MN273504). The percentage identity and the other alignment indices (Max score, Total score, and Query coverage) were the highest $(100 \%)$ when the DNA sequences were compared to $M$. guilliermondii and R. mucilaginosa sequences present in the NCBI database, confirming that the isolated species have the most similar DNA sequences to the above-mentioned species.

\subsection{The Antifungal Effect of A. satioum Extract}

The garlic extract inhibited the germination and the growth of $M$. guilliermondii on SDA. After three days of incubation, the control Petri dishes had white to cream colonies, of 11-12 $\mathrm{mm}$ in size, whereas the colonies from the experimental variants with plant extract had small colonies in accord with the concentration of garlic extract.

On SDA with $4 \%$ garlic extract, the colonies had 9-10 $\mathrm{mm}$ and those obtained on SDA with $8 \%$ extract had 3-4 mm. No colonies were identified on SDA with $12 \%(120 \mathrm{mg} / \mathrm{mL})$ garlic extract. Regarding naftifine hydrochloride the maximum of inhibition of M. guilliermondii colonies was $55-56 \%$ and corresponded to the concentration of $5 \%(500 \mu \mathrm{g} / \mathrm{mL})$. The inhibition of naftifine against M. guilliermondii was of $55-56 \%$ for the concentrations of 3\%, $4 \%$ and $5 \%$ respectively (Figure 3, Table 1 ).

The R. mucilaginosa control colonies were mucoid and had a diameter of 12-13 $\mathrm{mm}$ after 3 days of incubation on SDA. These colonies had red color because the cells possess a carotenoid biosynthetic pathway. On SDA with garlic extract the R. mucilaginosa colonies had red color and a smaller diameter than the control colonies according to the plant extract concentration. At the $4 \%$ garlic extract, the colonies had 10-11 mm and those obtained on SDA with $8 \%$ extract had 7-8 mm. The inhibitory effect of garlic extract against R. mucilaginosa was $22.5 \%$ in the case of $4 \%$ concentration and $90 \%$ for $12 \%$ concentration.

In the experimental variants with naftifine hydrochloride, the colonies had white color in comparison with the control. The inhibitory effect of naftifine hydrochloride against $R$. mucilaginosa was of $21 \%$ for $0.5 \%$ concentration and $90 \%$ for $2.5 \%$. Antifungal susceptibility test performed by the agar dilution method showed that garlic extract had a MIC of $14 \%(140 \mathrm{mg} / \mathrm{mL})$ against R. mucilaginosa isolate and the naftifine hydrochloride of $3 \%(300 \mu \mathrm{g} / \mathrm{mL})$. The results demonstrated that naftifine hydrochloride affected the carotenoid biosynthetic pathway producing depigmentation of cells growing on SDA (Figure 4, Table 2). The antifungal effect of garlic extract against the yeasts 
was compared to naftifine. Based on MIC determination the R. mucilaginosa isolate was significantly more susceptible to the naftifine, in general, than the M. guilliermondii isolate.
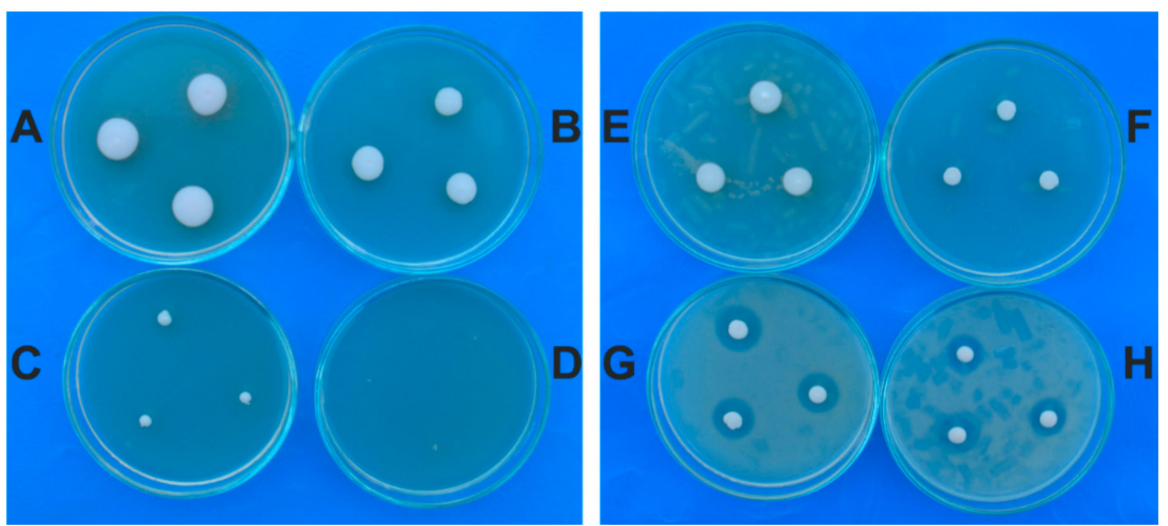

Figure 3. Colonies of M. guilliermondii on SDA: control (A); with garlic extract 4\% (B); with garlic extract $8 \%(C)$; with garlic extract $12 \%$ (without colony) (D); with naftifine $0,5 \%$ (E); with naftifine $1 \%$ (F); with naftifine 3\% (G); with naftifine 5\% (H).

Table 1. In vitro effect of $A$. sativum extract and naftifine against M. guilliermondii isolate using the agar dilution method.

\begin{tabular}{cccccc}
\hline $\begin{array}{c}\text { Garlic Extract } \\
\text { Concentration (\%) }\end{array}$ & $\begin{array}{c}\text { Colony } \mathbf{a} \\
\text { Diameter (mm) }\end{array}$ & $\mathbf{P}^{\mathbf{a}}$ & $\begin{array}{c}\text { Naftifine Solution } \\
\text { Concentration (\%) }\end{array}$ & $\begin{array}{c}\text { Colony } \\
\mathbf{b} \\
\text { Diameter (mm) }\end{array}$ & $\mathbf{P}^{\mathbf{b}}$ \\
\hline $\mathrm{C}$ & $11.66 \pm 0.81$ & 0 & $\mathrm{C}$ & $11.66 \pm 0.81$ & 0 \\
2 & $11.16 \pm 0.40$ & $4.28 \pm 0.40$ & 0.5 & $10.0 \pm 0.63$ & $14.23 \pm 0.63$ \\
4 & $9.66 \pm 0.51$ & $17.15 \pm 0.51$ & 1 & $8.33 \pm 0.51$ & $28.55 \pm 0.51$ \\
6 & $6.66 \pm 0.51$ & $42.88 \pm 0.51$ & 2 & $6.83 \pm 0.83$ & $41.42 \pm 0.83$ \\
8 & $3.50 \pm 0.54$ & $69.98 \pm 0.54$ & 3 & $5.16 \pm 0.40$ & $55.74 \pm 0.40$ \\
10 & $1.33 \pm 0.51$ & $88.59 \pm 0.51$ & 4 & $5.16 \pm 0.40$ & $55.74 \pm 0.40$ \\
12 & 0 & 100 & 5 & $5.16 \pm 0.40$ & $55.74 \pm 0.40$ \\
\hline
\end{tabular}

${ }^{a}$ the effect of A. sativum extract; ${ }^{\mathrm{b}}$ the effect of naftifine solution; C control (20\% aq. EtOH); P mycelial growth inhibition - results are the mean \pm SD of six experiments.
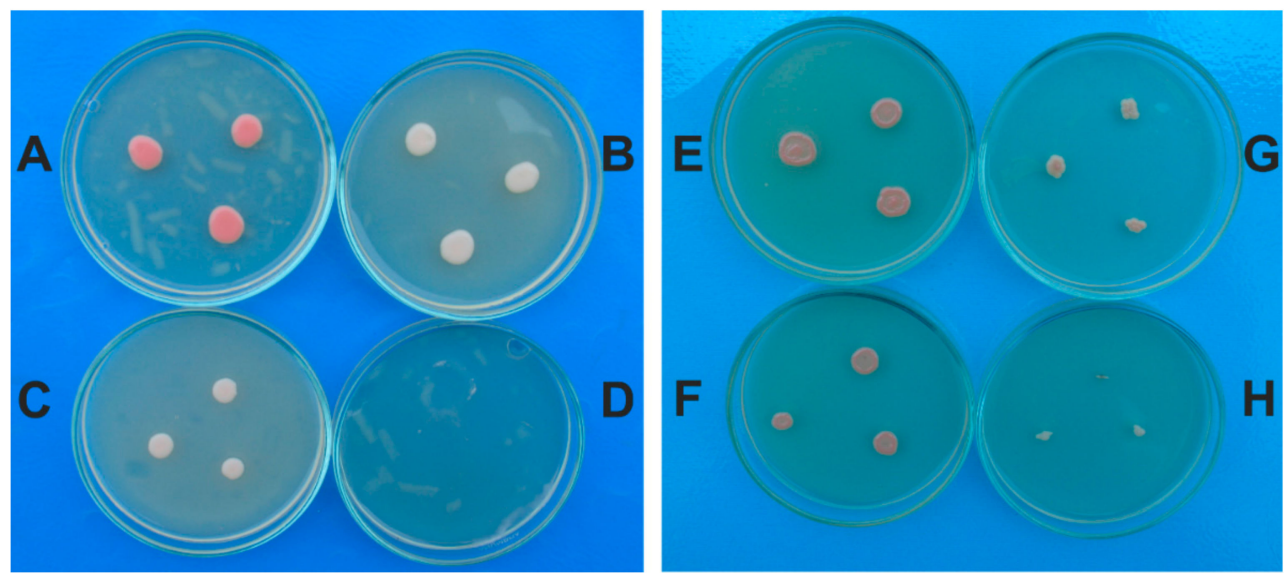

Figure 4. Colonies of R. mucilaginosa on SDA: with garlic extract 4\% (A); with garlic extract 6\% (B); with garlic extract $8 \%(\mathbf{C})$; with garlic extract $10 \%(\mathbf{D})$; control (E); with naftifine $0.1 \%(\mathbf{F})$; with naftifine $1.5 \%(\mathrm{G})$; with naftifine $3 \%$ (without colony) (H). 
Table 2. In vitro effect of $A$. sativum extract and naftifine against $R$. mucilaginosa isolate using the agar dilution method.

\begin{tabular}{cccccc}
\hline $\begin{array}{c}\text { Garlic Extract } \\
\text { Concentration (\%) }\end{array}$ & $\begin{array}{c}\text { Colony }^{\mathbf{a}} \\
\text { Diameter (mm) }\end{array}$ & $\mathbf{P}^{\mathbf{a}}$ & $\begin{array}{c}\text { Naftifine Solution } \\
\text { Concentration (\%) }\end{array}$ & $\begin{array}{c}\text { Colony }^{\mathbf{b}} \\
\text { Diameter (mm) }\end{array}$ & $\mathbf{P}^{\mathbf{b}}$ \\
\hline C & $13.33 \pm 0.51$ & 0 & $\mathrm{C}$ & $13.33 \pm 0.51$ & 0 \\
2 & $12.16 \pm 0.75$ & $8.77 \pm 0.75$ & 0.1 & $12.83 \pm 0.40$ & $3.75 \pm 0.40$ \\
4 & $10.33 \pm 0.51$ & $22.50 \pm 0.51$ & 0.5 & $10.5 \pm 0.54$ & $21.23 \pm 0.54$ \\
6 & $9.0 \pm 0.63$ & $32.48 \pm 0.63$ & 1.0 & $7.83 \pm 0.40$ & $41.26 \pm 0.40$ \\
8 & $7.33 \pm 0.57$ & $45.01 \pm 0.57$ & 1.5 & $6.33 \pm 0.51$ & $52.51 \pm 0.51$ \\
10 & $4.0 \pm 0.63$ & $69.99 \pm 0.63$ & 2 & $3.66 \pm 0.81$ & $72.54 \pm 0.81$ \\
12 & $1.33 \pm 0.51$ & $90.02 \pm 0.51$ & 2.5 & $1.33 \pm 0.51$ & $90.02 \pm 0.51$ \\
14 & & 100 & 3.0 & 0 & 100 \\
\hline
\end{tabular}

a the effect of $A$. sativum extract; ${ }^{b}$ the effect of naftifine solution; C control (20\% aq. EtOH); P = mycelial growth inhibition - results are the mean \pm SD of 6 experiments.

\subsection{Ultrastructural Changes Produced by A. sativum Extract}

On the TEM micrographs of the M. guilliermondii control cells the cellular organelles such as the cellular wall, plasmalemma, vacuole, mitochondria, and nucleus respectively, were clearly visible (Figure 5A-D). The distinctive cell wall layers are the inner cell wall layer adjacent to the plasmalemma and the electron-dense external cell wall layer (Figure 5C). The MIC of garlic extract penetrated the cellular and the organelles membrane of $M$. guilliermondii and caused the alteration and precipitation of the cytoplasmic content in all treated cells (Figure 5E,F). Because of the cytoplasmic alterations, the nucleus and the cell organelles were destroyed, resulting in cell death.

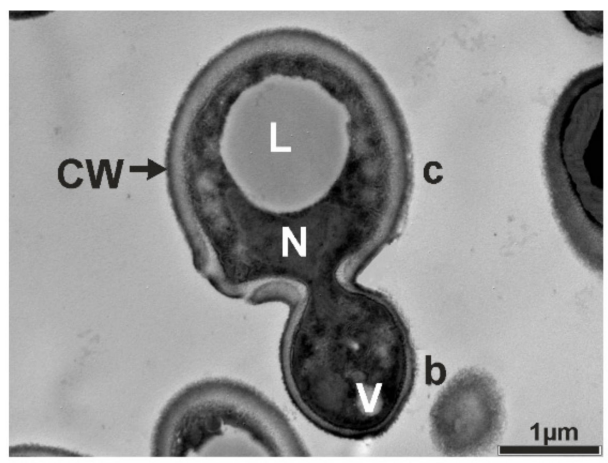

A

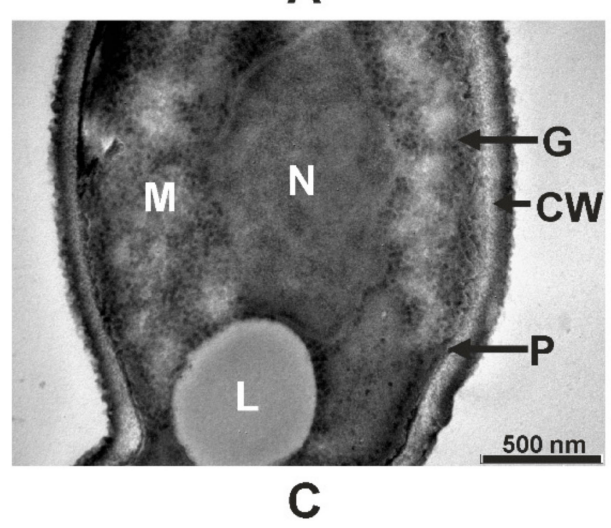

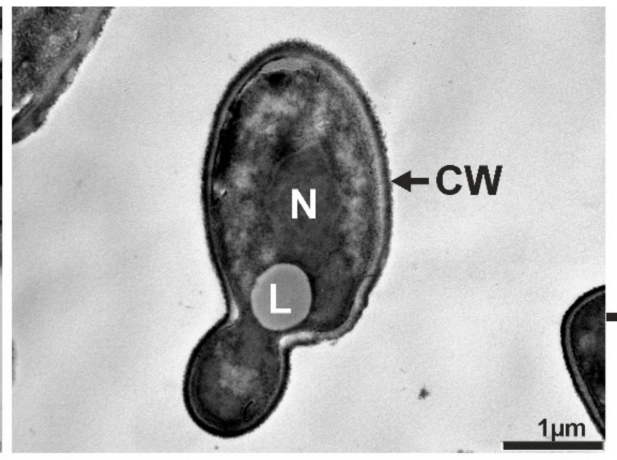

B

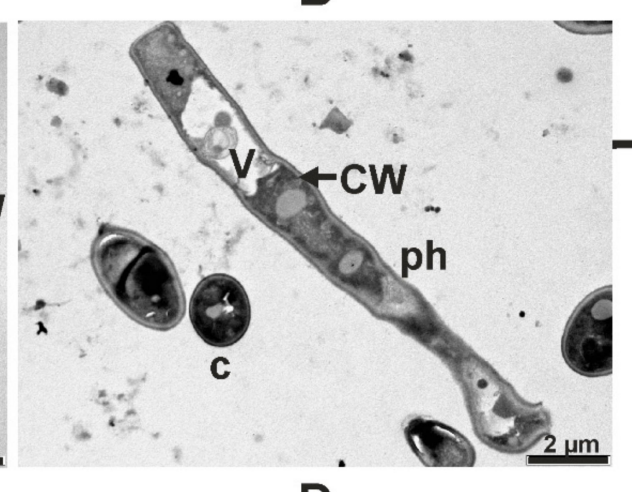

D control cells

Figure 5. Cont. 


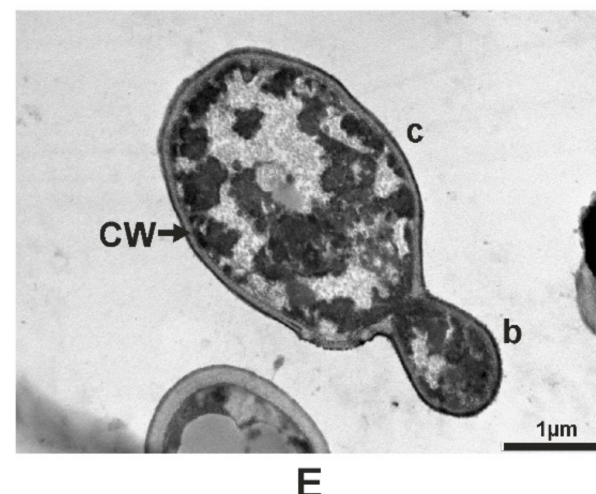

E

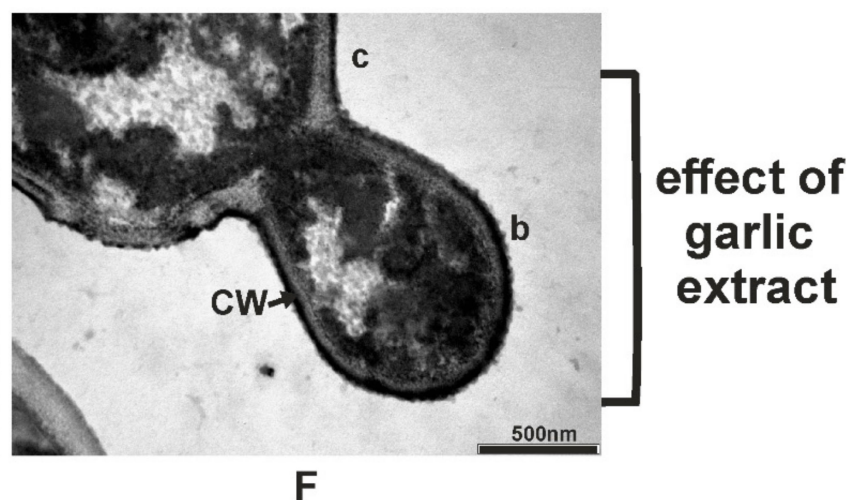

$\mathbf{F}$

Figure 5. Transmission electron micrographs of M. guilliermondii showing ultrastructural components of control cells: longitudinal section of bud and cell (A,B); longitudinal section of cell (detailed) (C); longitudinal section of pseudohyphae (ph) and cross section of cells (D), and the changes produced by garlic extract in $12 \%$ minimum inhibitory concentration: longitudinal section of cell (E) longitudinal section of cell (detailed) (F). Legend: b, bud; c, cell; CW, cell wall; G, glycogen; L, lipid; M, mitochondrion; $\mathrm{N}$, nucleus; $\mathrm{P}$, plasmalemma; $\mathrm{V}$, vacuole.

Like previously described, the ultrastructural characteristics of R. mucilaginosa control cells included the electron-dense and lamellate cell wall, plasmalemma, endoplasmic reticulum, mitochondrion, lipid and glycogen accumulation in the cytoplasm, and spherical to ovoid nucleus. In the cytoplasm of young cells were found numerous small lipid granules of uniform size and in mature and senescent cells were found larger lipid granules with variable shapes generated by fusion (Figure 6A-D). The A. sativum extract at MIC caused irreversible ultrastructural changes in R. mucilaginosa treated cells determining the loss of the structural integrity and affecting the germination capacity. The alteration and the precipitation of the cytoplasmic content, destroyed nucleus and cell organelles resulted in cell death (Figure 6E,F).

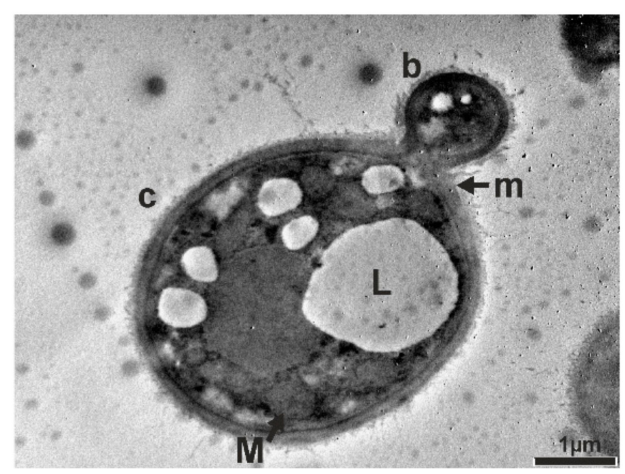

A

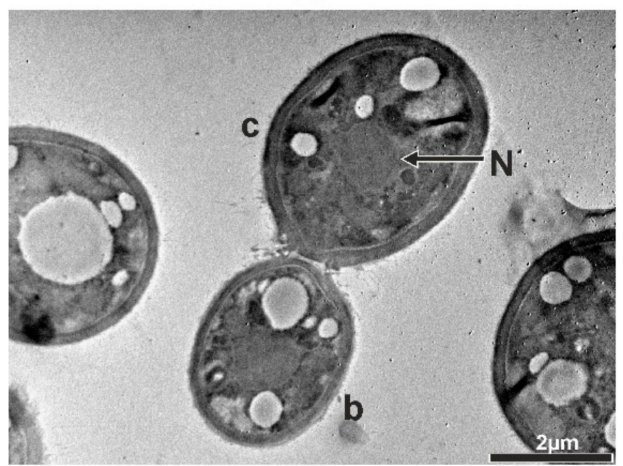

C

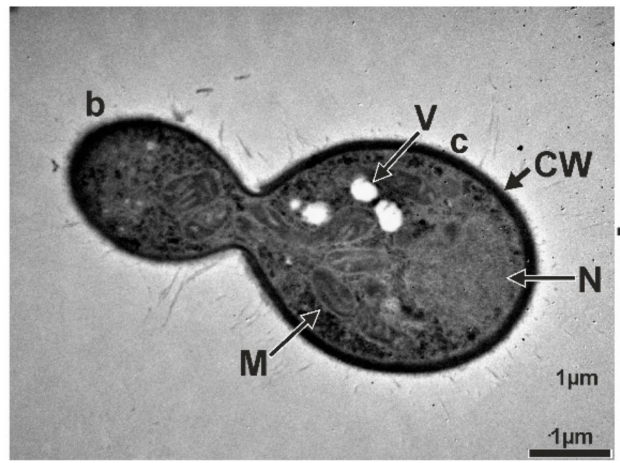

B

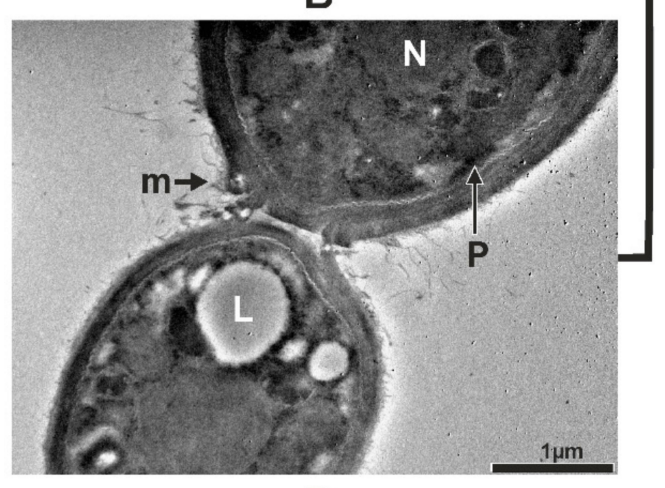

D control cells

Figure 6. Cont. 


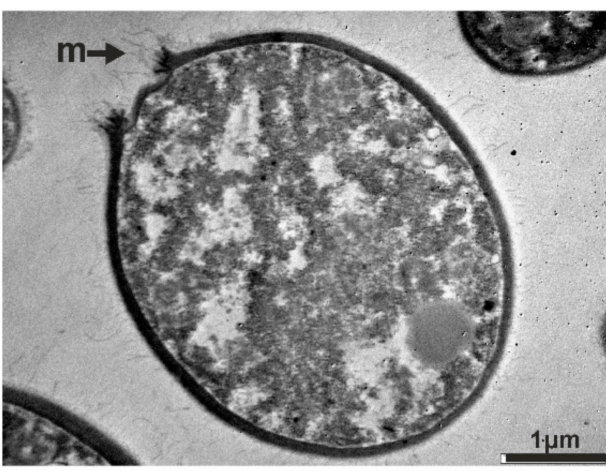

$\mathbf{E}$

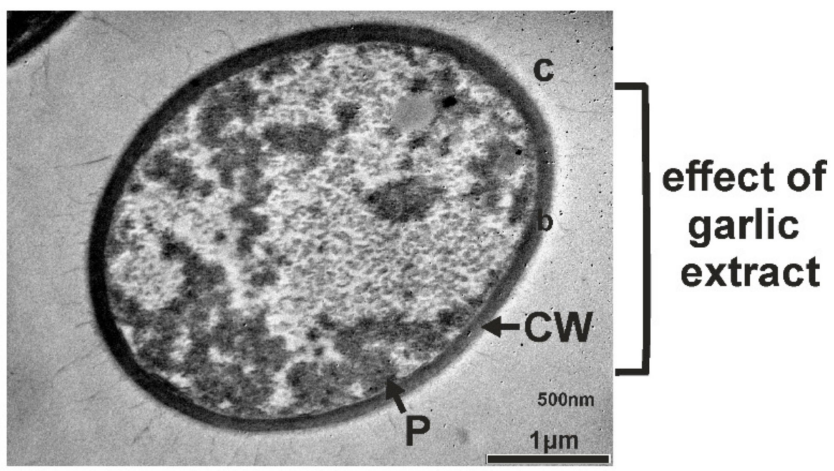

$\mathbf{F}$

Figure 6. Transmission electron micrographs of R. mucilaginosa showing ultrastructural components of control cells: longitudinal section of bud and cell $(\mathbf{A}, \mathbf{B}, \mathbf{C})$; longitudinal section of cell and bud (detailed) (D), and the changes produced by garlic extract in $14 \%$ minimum inhibitory concentration: longitudinal section of cell (E), cross section of cell (F). Legend: b, bud; c, cell; CW, cell wall; ER, endoplasmic reticulum; $\mathrm{G}$, glycogen; $\mathrm{L}$, lipid; $\mathrm{M}$, mitochondrion; $\mathrm{m}$, mucilage; $\mathrm{N}$, nucleus; $\mathrm{P}$, plasmalemma; $\mathrm{V}$, vacuole.

\subsection{Antioxidant Properties Evaluation}

The in vitro antioxidant activity of the $A$. sativum tested extract was investigated using the most frequently used methods, the 2,2' -azino-bis-3-ethylbenzthiazoline-6-sulphonic acid (ABTS) and 1,1-diphenyl-2-picrylhydrazyl (DPPH) bleaching assays. The activity was higher when the ABST bleaching assay was used compared to the DDPH bleaching assay (Figure 7A).

A.

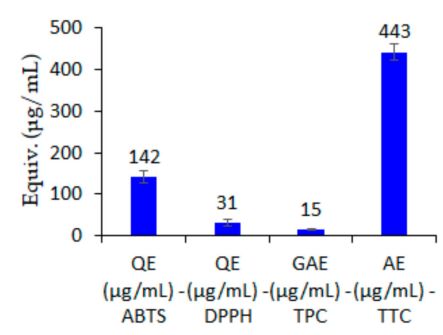

B.

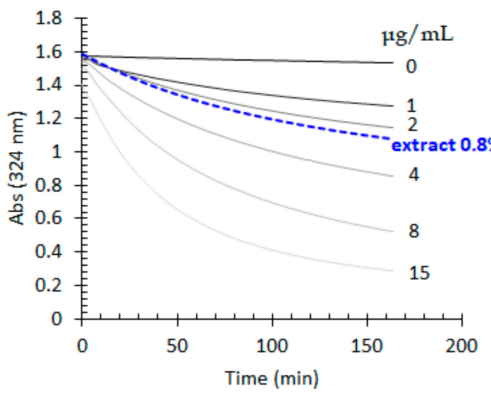

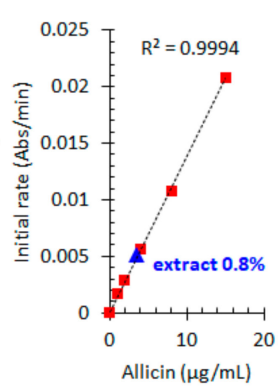

Figure 7. (A) In vitro antioxidant activity evaluated using ABTS and DPPH scavenging assays and expressed as quercetin equivalents (QE), total phenolic content (TPC) determined using Folin-Ciolalteau reagent and expressed as gallic acid equivalents (GAE) and total thiosulfinate content (TTC) and expressed in allicin equivalents (AE), $n=3$, error bars are standard deviations (B) Kinetic determination of total thiosulfinate content of the studied A. sativum extract $(0.8 \%)$ using Miron et al. [22] kinetic assay and the allicin standards $(0-15 \mu \mathrm{g} / \mathrm{mL})$ and the corresponding calibration curve.

In vivo antioxidant effect of $A$. sativum extract evaluated on a rat experimental acute inflammation model was performed by measuring systemic oxidative stress markers. The effects were compared to diclofenac, an anti-inflammatory drug, and to allicin, the main compound from phytochemical analysis of the tested extract. Important increases in serum Oxidative Stress Index (OSI) $(p<0.001)$ and Total Oxidative Status (TOS) $(p<0.001)$ with concomitant decrease in Total Antioxidant Response (TAR) $(p<$ 0.01 ) were seen in the animals from the Inflammation group (INFLAM). A. sativum treatments resulted in a substantial decrease in the levels of TOS $(p<0.01)$ and OSI $(p<0.01)$ and no important changes in TAR $(p<0.05)$ for all tested dilutions. On TOS allicin $(p<0.01)$ had similar effect ass A. sativum, but diclofenac $(p<0.01)$ had lower inhibitory effects (Table 3$)$. 
Table 3. In vivo serum oxidative stress markers.

\begin{tabular}{|c|c|c|c|c|c|c|}
\hline & $\begin{array}{c}\text { TOS } \\
\left(\mu \mathrm{mol} \mathrm{H}_{2} \mathrm{O}_{2}\right. \\
\text { equiv/L) }\end{array}$ & $\begin{array}{c}\text { TAR (mmol } \\
\text { trolox equiv/L) }\end{array}$ & OSI & $\begin{array}{c}\mathrm{NOx} \\
(\mu \mathrm{mol} / \mathrm{L})\end{array}$ & MDA (nmol/mL) & $\begin{array}{l}\text { SH mmol } \\
\text { (TSH/mL) }\end{array}$ \\
\hline Control & $\begin{array}{c}38.22 \pm 4.77 \\
a^{* * *}\end{array}$ & $\begin{array}{c}1.0897 \pm 0.0014 \\
a^{* *}\end{array}$ & $\begin{array}{c}35.04 \pm 4.39 \\
a^{* * *}\end{array}$ & $\begin{array}{c}52.88 \pm 2.60 \\
\mathrm{a}^{* * *}\end{array}$ & $\begin{array}{c}5.82 \pm 0.56 \\
a^{* * *}\end{array}$ & $\begin{array}{c}0.67 \pm 0.07 \\
a^{* * *}\end{array}$ \\
\hline Inflammation & $\begin{array}{c}66.35 \pm 8.49 \\
b^{* *}, c^{*}\end{array}$ & $\begin{array}{c}1.0891 \pm 0.0009 \\
b^{*}, c^{*}\end{array}$ & $\begin{array}{c}60.90 \pm 7.81 \\
b^{* *}, c^{*}\end{array}$ & $\begin{array}{c}82.42 \pm 0.27 \\
b^{* * *}, c^{* *}\end{array}$ & $\begin{array}{c}7.50 \pm 0.77 \\
b^{* * *}, c^{*}\end{array}$ & $\begin{array}{c}0.50 \pm 0.08 \\
b^{* *}, c^{*}\end{array}$ \\
\hline Diclofenac & $\begin{array}{c}48.65 \pm 8.36 \\
a^{* *}, b^{*}\end{array}$ & $\begin{array}{c}1.0970 \pm 0.0017 \\
\mathrm{~b}^{*}\end{array}$ & $\begin{array}{c}44.47 \pm 7.59 \\
\mathrm{a}^{* * *}, \mathrm{~b}^{*}\end{array}$ & $\begin{array}{c}58.71 \pm 5.29 \\
a^{* *}, b^{*}\end{array}$ & $\begin{array}{c}5.75 \pm 0.80 \\
\mathrm{a}^{* *}, \mathrm{~b}^{*}\end{array}$ & $\begin{array}{c}0.71 \pm 0.11 \\
a^{* *}, b^{*}\end{array}$ \\
\hline Allicin & $\begin{array}{c}33.76 \pm 4.82 \\
a^{* *}, c^{*}\end{array}$ & $\begin{array}{c}1.0884 \pm 0.0005 \\
\mathrm{a}^{*}, \mathrm{c}^{*}\end{array}$ & $\begin{array}{c}31.02 \pm 4.43 \\
a^{* *}, c^{*}\end{array}$ & $\begin{array}{c}40.30 \pm 6.12 \\
a^{* * *}, c^{*}\end{array}$ & $\begin{array}{c}5.57 \pm 0.48 \\
\mathrm{a}^{* *}, \mathrm{c}^{*}\end{array}$ & $\begin{array}{c}0.75 \pm 0.13 \\
a^{* *}, c^{*}\end{array}$ \\
\hline $\begin{array}{c}\text { A. sativum } \\
100 \%\end{array}$ & $\begin{array}{c}33.13 \pm 8.06 \\
a^{* *}, b^{*}, c^{*}\end{array}$ & $\begin{array}{c}1.0894 \pm 0.0009 \\
a^{*}, b^{*}, c^{*}\end{array}$ & $\begin{array}{c}30.43 \pm 7.39 \\
a^{* *}, b^{*}, c^{*}\end{array}$ & $\begin{array}{l}38.12 \pm 7.57 \\
a^{* * *}, b^{*}, c^{* *}\end{array}$ & $\begin{array}{c}5.54 \pm 0.32 \\
a^{* *}, b^{*}, c^{*}\end{array}$ & $\begin{array}{c}0.60 \pm 0.09 \\
a^{* *}, b^{*}, c^{*}\end{array}$ \\
\hline $\begin{array}{c}\text { A. sativum } \\
50 \%\end{array}$ & $\begin{array}{c}31.88 \pm 6.91 \\
a^{* *}, b^{*}, c^{*}\end{array}$ & $\begin{array}{c}1.0884 \pm 0.0009 \\
a^{*}, b^{*}, c^{*}\end{array}$ & $\begin{array}{c}29.27 \pm 6.34 \\
a^{* *}, b^{*}, c^{*}\end{array}$ & $\begin{array}{l}38.15 \pm 8.10 \\
a^{* * *}, b^{*}, c^{* *}\end{array}$ & $\begin{array}{c}5.48 \pm 0.63 \\
a^{* *}, b^{*}, c^{*}\end{array}$ & $\begin{array}{l}0.81 \pm 0.29 \\
a^{* * *}, b^{*}, c^{*}\end{array}$ \\
\hline $\begin{array}{c}\text { A. sativum } \\
25 \%\end{array}$ & $\begin{array}{c}32.25 \pm 3.75 \\
a^{* *}, b^{*}, c^{*}\end{array}$ & $\begin{array}{c}1.0884 \pm 0.0005 \\
a^{*}, b^{*}, c^{*}\end{array}$ & $\begin{array}{c}29.63 \pm 3.43 \\
a^{* *}, b^{*}, c^{*}\end{array}$ & $\begin{array}{c}53.91 \pm 8.83 \\
\mathrm{a}^{* *}, \mathrm{~b}^{*}, \mathrm{c}^{*}\end{array}$ & $\begin{array}{c}5.79 \pm 0.51 \\
a^{* *}, b^{*}, c^{*}\end{array}$ & $\begin{array}{c}0.62 \pm 0.15 \\
a^{* *}, b^{*}, c^{*}\end{array}$ \\
\hline
\end{tabular}

Values are expressed as average \pm standard deviation (SD) $(n=5)$. TOS: total oxidative status; TAR: total antioxidant reactivity; OSI: oxidative stress index; NOx: nitrites and nitrates; SH: total thiols; MDA: malondialdehyde, SH total thiols. a vs INFLAM; $\mathrm{b}$ vs Allicin; $\mathrm{c}$ vs DICLOFENAC; $p>0.05^{*} ; p<0.01^{* *} ; p<0.001^{* * *}$.

Serum nitrites and nitrates (NOx) were substantially elevated in the INFL group $(p<0.001)$ as compared to the control rats. The treatment with A. sativum extracts $100 \%(p<0.001)$ and $50 \%(p<$ 0.001 ) induced a very important reduction of NOx production, but $A$. sativum extract $25 \%$ was less efficient $(p<0.01)$. Allicin was also a good inhibitor of NOx $(p<0.01)$, and this effect was comparable to A. sativum $100 \%$ and $50 \%$, and better than diclofenac $(p<0.01)$. There was no considerable statistical difference between $A$. sativum extract $25 \%$ and diclofenac in terms of NOx production $(p>0.05$, Table 3$)$. Total thiols $(\mathrm{SH})$ were reduced in the INFLAM group $(p<0.001)$, and the treatments with allicin and diclofenac caused an important increase of SH $(p<0.001)$. A. sativum extract $50 \%$ had smaller stimulatory effect on the $\mathrm{SH}$ than the A. sativum extracts $100 \%$ and $25 \%(p<0.001$, Table 3$)$.

Inflammation was associated with a considerable elevation of MDA $(p<0.001)$, and all A. sativum extract dilutions $25 \%$ reduced MDA production $(p<0.01)$. Allicin and diclofenac were equally efficient on MDA reduction $(p<0.01)$, and similar to A. sativum extract (Table 3$)$.

\section{Discussion}

Our study presents for the first time a clinical case of toenail total dystrophic onychomycosis due to a mixed infection associating M. guilliermondii and R. mucilaginosa, and showed that the garlic extract had antifungal effect against the two species.

Onychomycosis is a multifactorial disease. Based on morphologic patterns and mode of nail invasion it was divided into several classes [23]: distal and lateral subungual onychomycosis; proximal subungual onychomycosis; superficial onychomycosis; total dystrophic onychomycosis; endonyx subungual onychomycosis, which is rare. Some nails have features from a combination of classes [1]. Usually the main causative agent of onychomycosis is only one fungus [2], but mixed infections of dermatophytes and NDM or of dermatophytes and yeasts [10] in individuals with this disease were reported too. Since onychomycosis is caused by different fungal species, their precise and correct identification is very important in order to select the most appropriate antifungal therapy [11].

In our study, the identification of the fungi M. guilliermondii and R. mucilaginosa was made by morphological and cultural characteristics of the colonies obtained on SDA and confirmed by DNA molecular analysis. It is known that Allium plants are rich in active compounds such as alliin, allicin, ajoene, sterols, flavonoids, and phenolic acids [24]. The phytochemical analysis of the A. sativum extract found an important content of alliin and allicin. Besides the sulphur-containing compounds, garlic is also known to contain some phenolic compounds, mostly in the form of phenolic acids [25] known to have antioxidant and anti-inflammatory properties [24]. The chromatographic method 
employed led to the identification of only four phenolic acids and no flavonoid, even though other Allium species are known to contain high amounts of flavonoids [26].

Allicin is one of the most important bioactive compounds from Allium species that exhibits antioxidant and antifungal, antibacterial, antiviral, antiparasitic activity and is effective against many fungal species [27]. The garlic extract inhibited the germination and the growth of M. guilliermondii and R. mucilaginosa on SDA. Our results are in accord with literature data regarding antifungal effect of A. sativum extract against human pathogenic fungi like Candida species [4], Trichophyton mentagrophytes, T. rubrum, T. verrucosum, Microsporum gypseum and Epidermophyton floccosum etc. Therefore, garlic extract exhibited a fungicidal effect against Candida albicans, C. tropicalis and C. krusei at the concentration of $100 \mathrm{mg} / \mathrm{mL}$. The extract fully suppressed the production of hyphae by Candida albicans even at the lowest concentration tested, of $20 \mathrm{mg} / \mathrm{mL}$. On the other hand, the MIC of garlic oil against C. albicans was $0.35 \mu \mathrm{g} / \mathrm{mL}$ [4].

The effect of garlic extract against R. mucilaginosa isolate causing onychomycosis is not mentioned in the literature. For treatment of Rhodotorula infections different chemicals and plant extracts (Punica granatum, Salvia officinalis, Laurus nobilis, and Thymbra spicata) were tested [28].

The garlic extract affected the fungal cell wall, which is a complex and dynamic structure, a contact surface with the host environment, but in the same time antifungal treatment target [5]. The A. sativum extract had fungicidal effect by causing irreversible ultrastructural changes in M. guilliermondii and R. mucilaginosa cells, which determined loss of structural integrity and affected the germination capacity. The alteration and precipitation of the cytoplasmic content, destroyed nucleus and cell organelles resulted in cell death. Our results are in accord with those obtained in the treatment of Candida albicans with garlic oil in MIC of $0.35 \mu \mathrm{g} / \mathrm{mL}$ [4].

The ultrastructural changes induced by the A. sativum extract may be correlated to the antifungal compounds, recommending the extract as an alternative in the treatment of dermatophytic fungi, Candida isolates [4]. Generally, efficient antioxidant plant extracts contain compounds that also display antimicrobial activity [29]. By using plant extracts, rich in natural antioxidants, oxidative stress can be reduced. The in vitro antioxidant activity of the tested extract was higher when ABST bleaching assay was used compared to DDPH bleaching assay. This indicates that a mechanism of electron transfer predominates compared to hydrogen atom transfer, suggesting a higher contribution of sulphur-containing agents (i.e., thiosulfinates, sulphides, etc.) rather than phenolic compounds which usually act as hydrogen atom transfer. Our phytochemical analysis confirmed the higher allin and allicin contents of the $A$. sativum extract.

Because it was found that some extracts exhibit antioxidant activity both in vitro and in vivo, but for other extracts, the in vitro antioxidant activity does not apply to in vivo models, we further tested the in vivo antioxidant effects. Furthermore, it was known that in vitro and in vivo antioxidant effects may not correspond because polyphenols may also act as prooxidants via Fenton reaction [24].

In vivo, the $A$. sativum extract effect consisted in oxidant reduction. Oxidant reduction was evidentiated by measuring TOS, NO and MDA. Endogenous nitric oxide (NO) is synthesized from L-arginine by three major nitric oxide synthases: endothelial (eNOS), neural (nNOS), and inducible nitric oxide synthases (iNOS). NO produced by iNOS plays an important role in host defense. High level or prolonged induction of NO may lead to pathological consequences in inflammatory diseases due to the involvement in the oxidative stress. Reduction of serum NOx by A. sativum extracts was important, and followed the same pattern like TOS and OSI. MDA is a secondary product of lipid peroxidation. The inhibitory effect of the A. sativum extract on MDA production also shows that the extract is a good antioxidant.

Because the main compound of the extract was allicin, A. sativum extract effects were compared to allicin. Furthermore, because the antioxidant effect is anti-inflammatory, A. sativum activity was also compared to a nonsteroidal anti-inflammatory drug, diclofenac. Finally, it was found that $A$. sativum antioxidant activity was better or comparable with those of allicin and diclofenac. Considering that local or systemic inflammation may associate to onychomycosis, and oxidative stress is an injury 
mechanism in inflammation, $A$. sativum extracts antioxidant activity may recommend this product for local or systemic anti-inflammatory therapy in onychomycosis.

\section{Materials and Methods}

\subsection{Chemicals}

The chemicals used were naftifine (active substance in Exoderil (Sandoz GmbH, (Kundl, Austria)), Sabouraud dextrose agar (SDA), diclofenac (Sigma-Aldrich, (St. Louis, MO, USA)) and allicin (described in the Supplementary Materials). Below it says this was purchased from Aldrich.

\subsection{Allium sativum Extract}

Garlic (Allium sativum L.) bulbs were collected from a private garden of Cluj-Napoca. A voucher specimen (CL 666212) is deposited at the Herbarium of Babeş-Bolyai University, Cluj-Napoca, Romania. Fresh A. sativum bulb fragments of $0.5-1.0 \mathrm{~cm}$ were extracted with $60 \%$ ethanol (Merck, Bucureşti, Romania) by a cold repercolation method, at room temperature, for 3 days. The A. sativum extract, containing $1 \mathrm{~g}$ plant material in $1 \mathrm{~mL}$ of $20 \%$ ethanol (w:v/g:mL) was obtained by filtration.

\subsection{Phytochemical Analysis}

Two HPLC-DAD-MS protocols were optimized to separate and determine the main phytoconstituents of the studied extract; the first HPLC protocol was optimized for allicin and alliin determination and the second one for polyphenolic compounds determination. Total phenolic content (TPC) was determined using Folin Ciocalteu reagent and expressed in gallic acid equivalents as previously described [30]. Total thiosulfinate content (TTC) was determined using a kinetic assay based on 4-mercaptopyridine bleaching assay monitored at $324 \mathrm{~nm}$ as described by Miron et al. and was expressed in allicin equivalents based on a calibration curved constructed using this standard [22]. More information may be found in the Supplementary Materials.

\subsection{Fungal Strain Isolation and Growth Conditions}

The fungi R. mucilaginosa (A. Jörg.) F.C. Harrison and M. guilliermondii (Wick.) Kurtzman \& M. Suzuki (syn. Candida guilliermondii (Castell.) Langeron \& Guerra) were isolated from toenails affected by onychomycosis obtained from a patient woman of 88 years with chronic HBV hepatitis. After nail asepsis with $70 \%$ ethanol, the distal and lateral fragments of both toenail plates with subungual debris were removed with a sterile nail clipper.

The Ethics Committee of the Iuliu Haţieganu University of Medicine and Pharmacy, Cluj-Napoca (Romania) approved the study and informed written consent were obtained from the patient before enrolling her in the study. All experiments in this study were performed in accordance with relevant guidelines and regulations.

The R. mucilaginosa and M. guilliermondii fungal isolates were obtained using $2-3 \mathrm{~mm}$ toenail fragments disinfected in $20 \%$ ethanol for $1 \mathrm{~min}$ and inoculated onto SDA control media in Petri dishes. The fungal samples were identified by morphological and cultural characteristics of the colonies obtained by the standard method of triple culture (insemination of the inoculum in three points on the surface of SDA in Petri dishes) and after incubation at $22^{\circ} \mathrm{C}$ for 3 days. All experiments were run three times [31].

\subsection{Molecular Confirmation of the Fungi}

The species M. guilliermondii and R. mucilaginosa, isolated on SDA from a human toenail affected by onychomycosis were molecularly confirmed targeting the Internal Transcribed Spacer using the ITS1 and ITS2 primers [32]. The DNA extraction was performed using the commercial kit Animal and Fungi DNA Preparation Kit ${ }^{\circledR}$ (Jena Bioscience, Jena, Germany) according to manufacturers' protocol. The PCR (Polymerase chain reaction) amplification took place in a $25 \mu \mathrm{L}$ final volume of mixture reaction 
containing: 1X MangoTaq Colored Reaction Buffer (Bioline, London, UK), $2.5 \mathrm{mM} \mathrm{MgCl} 2$ (Bioline), $0.5 \mathrm{mM}$ dNTP (Bioline), $0.5 \mathrm{mM}$ of each primer (Macrogen Inc., Seoul, South Korea), $1.25 \mathrm{U} / \mu \mathrm{L}$ MangoTaq (Bioline) and $2 \mu \mathrm{L}$ of DNA. The amplification series consisted of 35 cycles of the following: $95{ }^{\circ} \mathrm{C}$ for $30 \mathrm{sec}, 56{ }^{\circ} \mathrm{C}$ for $30 \mathrm{sec}$ and $72{ }^{\circ} \mathrm{C}$ for $30 \mathrm{sec}$.

\subsection{The Antifungal Activity Evaluation}

In order to determine the effect of $A$. sativum extract, by agar dilution method, fungal cells were inoculated on SDA with different concentrations of garlic extract: $2 \%, 4 \%, 6 \%, 8 \%, 10 \%$, and $12 \%$ in case of $M$. guilliermondii and $2 \%, 4 \%, 6 \%, 8 \%, 10 \%, 12 \%$, and $14 \%$ for $R$. mucilaginosa. The negative control was without extract (nutritive medium and 20\% ethanol). An antifungal control with naftifine (Exoderil Sandoz GmbH Kundl, Austria - $10 \mathrm{mg}$ of naftifine hydrochloride/mL) was also used. In case of naftifine, experimental variants with $0.5 \%, 1 \%, 2 \%, 3 \%, 4 \%$, and $5 \%$ for $M$. guilliermondii and $0.1 \%, 0.5 \%$, $1 \%, 1.5 \%, 2 \%, 2.5 \%$, and $3 \%$ for $R$. mucilaginosa were performed. The antifungal activity of the A. sativum extract was expressed as MIC. The percentage of mycelial growth inhibition $(P)$ at each concentration was calculated using the formula $P=(C-T) \times 100 / C$, where $C$ is the diameter of the control colony and $T$ is the diameter of the treated colony [31].

\subsection{Electron Microscopy}

The morphology of the R. mucilaginosa and M. guilliermondii control cells was analyzed by scanning electron microscopy (SEM) using a JSM 5510 LV instrument (JEOL Co., Tokyo, Japan). The ultrastructure of the R. mucilaginosa and M. guilliermondii control cells and those treated for $1 \mathrm{~h}$ with the MIC of garlic extract were analyzed by TEM using a JEOL JEM 1010 electron microscope.

The fungal samples for electron microscopy were prepared according to literature [31] and the chemicals used were glutaraldehyde, resin (Epon 812), lead citrate, uranyl acetate, bismuth subnitrate (Electron Microscopy Sciences, Fort Washington, MD, USA), sticky carbon tabs, colloidal carbon coated grids (Agar Scientific, Cambridge, UK). Details regarding the sample work protocol for electron microscopy were presented in other reports [31].

\subsection{In Vitro Antioxidant Effect}

Antioxidant activity was evaluated using DPPH and ABTS radicals scavenging assays according to the protocols previously published [33] with the only difference that the results were expressed this time in quercetin equivalents obtained from calibration curves using quercetin as a standard $\left(R^{2}>0.995\right)$ for both assays.

\subsection{In Vivo Antioxidant Effect}

The experiments were carried out on male Albino Wistar rats, weighing 200-250 g, that were bred in the Animal Facility of Iuliu Haţieganu University of Medicine and Pharmacy, Cluj-Napoca. The animals were housed in controlled conditions $(12 \mathrm{~h}$ light/dark cycle, at an average temperature of $21-22{ }^{\circ} \mathrm{C}$ ), and had free access to standard pellet diet (Cantacuzino Institute, Bucharest, Romania) and water ad libitum. The animals were randomly assigned to seven groups $(n=5)$. A. sativum extract was administrated orally by gavage ( $1 \mathrm{~mL} / \mathrm{animal})$ in three dilutions $(100 \%, 50 \%$, and $25 \%)$ for seven days. Rats from the negative control group (CONTROL) and from the inflammation group (INFLAM) received by gavage for seven days tap water $(1 \mathrm{~mL} / \mathrm{animal})$. For seven days an anti-inflammatory control treated by gavage with diclofenac (DICLOFENAC) $(10 \mathrm{mg} / \mathrm{kg}$ body-weight (bw) for seven days, and a group treated by gavage with $1 \mathrm{~mL} /$ animal of allicin solution $(450 \mu \mathrm{g} / \mathrm{mL})$ were also used [34]. Allicin was purchased from Sigma-Aldrich (St. Louis, MO, USA) and diluted in water. The allicin dose corresponded to allicin concentration from one $\mathrm{mL}$ of undiluted A. sativum extract. In the 8th day, inflammation was induced by turpentine oil (i.m. $0,6 \mathrm{~mL} / \mathrm{kg} \mathrm{bw}$ ) in the animals treated with the extracts, in INFLAM, DICLOFENAC and allicin groups [19]. CONTROL animals were injected with $0.9 \%$ saline (i.m. $0.6 \mathrm{~mL} / \mathrm{kg} \mathrm{bw}$ ). Twenty-four hours after the inflammation induction, the rats 
were anesthetized using ketamine $(60 \mathrm{mg} / \mathrm{kg} \mathrm{bw})$ and xylazine $(15 \mathrm{mg} / \mathrm{kg} \mathrm{bw})$, blood was withdrawn by retro-orbital puncture, and serum was stored at $-80{ }^{\circ} \mathrm{C}$ until use. The in vivo experiments were performed in triplicate (Table 4). At the end of the experiment under general anesthesia, animals were killed by cervical dislocation [19].

Table 4. Flowchart of the in vivo experiment.

Day one

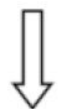

Day 8

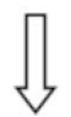

Day 9

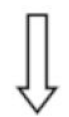

\begin{tabular}{|c|c|c|c|}
\hline Group & $\begin{array}{l}7 \text { Days Treatment by } \\
\text { Gavage: } 1 \mathrm{~mL} / \text { Animal }\end{array}$ & i.m. $0.6 \mathrm{~mL} / \mathrm{kg}$ bw & \\
\hline Control & tap water & saline solution & \multirow{7}{*}{$\begin{array}{l}\text { Blood collection under } \\
\text { general anesthesia }\end{array}$} \\
\hline Inflammation & tap water & turpentine oil & \\
\hline Diclofenac & $10 \mathrm{mg} / \mathrm{kg}$ bw & turpentine oil & \\
\hline Allicin & $450 \mu \mathrm{g} / \mathrm{mL}$ & turpentine oil & \\
\hline A. sativum $100 \%$ & $1 \mathrm{~mL} /$ animal & turpentine oil & \\
\hline A. sativum $50 \%$ & $1 \mathrm{~mL} /$ animal & turpentine oil & \\
\hline A. sativum $25 \%$ & $1 \mathrm{~mL} /$ animal & turpentine oil & \\
\hline
\end{tabular}

All treatments that involved animals were rigorously in accordance with EU Directive 2010/63/EU (European guidelines and rules). The Research Ethics Committee from Iuliu Haţieganu University of Medicine and Pharmacy Cluj-Napoca approved the research protocol (22/2016).

\subsection{Systemic Oxidative Stress Markers Determination}

The TOS of the serum was measured by a colorimetric assay and the results are expressed in $\mu$ mol $\mathrm{H}_{2} \mathrm{O}_{2}$ equiv/L. Serum total antioxidant response (TAR) was measured by using a colorimetric assay, and results are expressed as mmol Trolox equiv/L. The oxidative stress index (OSI), an indicator of the degree of oxidative stress was calculated: OSI (arbitrary unit) $=\mathrm{TOS}\left(\mathrm{mol} \mathrm{H}_{2} \mathrm{O}_{2}\right.$ equiv/L)/TAR(mmol Trolox equiv/L) [35].

The Griess reaction was used to indirectly determine nitric oxide synthesis by measuring NOx and the results were expressed as nitrite $\mu \mathrm{mol} / \mathrm{L}$ [35]. Malondialdehyde (MDA), a lipid peroxidation marker, was measured using thiobarbituric acid and the results were expressed as nmol/mL of serum. Total thiols (SH) were estimated using Ellman's reagent and the results were expressed as mmol $\mathrm{GSH} / \mathrm{mL}$ [36]. All serum spectrophotometric measurements were performed using a Jasco V-530 UV-Vis spectrophotometer (Jasco International Co. Ltd., Tokyo, Japan).

\subsection{Statistical Analysis}

Statistical analyses were performed using the program R environment, version 2.14.1. The results for each group were expressed as mean $\pm \mathrm{SD}$. Data were evaluated by analysis of variance (ANOVA) followed by Bonferroni-Holm posthoc test. A $p$ value of $\leq 0.05$ was considered statistically significant. The correlation analysis was performed by the Pearson test.

\section{Conclusions}

The findings of this study have shown for the first time that toenail onychomycosis may be determined by a mixed infection associating the yeasts $M$. guilliermondii and R. mucilaginosa 
and completed the list of aetiologic agents of this disease. Since the A. sativum extract had antifungal effect against $M$. guilliermondii and $R$. mucilaginosa isolates causing onychomycosis, this extract can be an attractive or a complementary alternative to common antifungal drugs. Due to the antioxidant effect, A. sativum extracts may target in the same time the oxidative stress from the inflammation associated to onychomycosis. The mechanisms of action of garlic constituents in vivo still require much research.

\section{Data Availability}

The datasets generated during and/or analyzed during the current study are available from the corresponding author on reasonable request.

Supplementary Materials: The following are available online at http://www.mdpi.com/1420-3049/24/21/3958/s1, Figure S1. A. Chromatographic separation (210 nm detection) of the A. sativum extract for alliin and allicin determination and the MS and UV-vis absorption molecular spectra of the two separated compounds. B. Chromatographic separation $(260 \mathrm{~nm}$ detection) of the A. sativum extract for phenolics determination and the UV-vis absorption molecular spectra of the four determined compounds (1 - gentisic acid, 2 - chlorogenic acid, 3 - 4-hydroxybenzoic acid, 6 - p-coumaric acid). Figure S2. A. Mean UV-vis absorption molecular spectra of $A$. sativum main chromatographic peaks and of the standards, indicating the two classes, phenolics and non-phenolics compounds. B. Scatterplot of the first two components in the Principal Component Analysis (PCA) applied on the UV-vis spectra. Standards are indicated by name while the main chromatographic peaks are labelled with S1-S14. Table S1. Elution time, analytical method characteristics and determined concentrations of alliin and allicin in the studied A. sativum extract $(n=4)$. Table S2. Elution time, analytical method characteristics and determined concentrations of phenolic acids and flavonoids in the studied A. sativum extract $(n=4)$.

Author Contributions: M.P. and C.A.M. conceived and designed the experiments, C.A.M. performed HPLC-DAD-MS analysis, in vitro antioxidant activity, statistical and data analysis, A.E.P., L.S., and A.B.T. performed in vivo antioxidant activity and electron microscopy studies and analyzed the data, O.R.-C. and C.M. performed fungal culture growing and molecular confirmation, M.P. and C.A.M. wrote the paper. All authors reviewed the manuscript.

Funding: This work was partly supported by UBB-TeMATIC Art P_40_374, project co-financed by FEDR through Competitiveness Operational Programme 2014-2020.

Conflicts of Interest: The authors declare no conflict of interest.

\section{References}

1. Westerberg, D.P.; Voyack, M.J. Onychomycosis: Current trends in diagnosis and treatment. Am. Fam. Physician 2013, 88, 762-770. [PubMed]

2. Welsh, O.; Vera-Cabrera, L.; Welsh, E. Onychomycosis. Clin. Derm. 2010, 28, 151-159. [CrossRef] [PubMed]

3. Martínez-Herrera, E.O.; Arroyo-Camarena, S.; Tejada-García, D.L.; Porras-López, C.F.; Arenas, R. Onychomycosis due to opportunistic molds. An. Bras. Derm. 2015, 90, 334-337. [CrossRef] [PubMed]

4. Li, W.-R.; Shi, Q.-S.; Dai, H.-Q.; Liang, Q.; Xie, X.-B.; Huang, X.-M.; Zhao, G.-Z.; Zhang, L.-X. Antifungal activity, kinetics and molecular mechanism of action of garlic oil against Candida albicans. Sci. Rep. 2016, 6, 22805. [CrossRef]

5. Nogueira, M.; Istel, F.; Jenull, S.; Walker, L.; Gow, N.; Lion, T. Quantitative Analysis of Candida Cell Wall Components by Flow Cytometrywith Triple-Fluorescence Staining. J. Microbiol. Mod. Tech. 2017.

6. Pfaller, M.; Diekema, D.; Mendez, M.; Kibbler, C.; Erzsebet, P.; Chang, S.-C.; Gibbs, D.; Newell, V.; Group, G.A.S. Candida guilliermondii, an opportunistic fungal pathogen with decreased susceptibility to fluconazole: Geographic and temporal trends from the ARTEMIS DISK antifungal surveillance program. J. Clin. Microbiol. 2006, 44, 3551-3556. [CrossRef]

7. Schwarzmüller, T.; Ma, B.; Hiller, E.; Istel, F.; Tscherner, M.; Brunke, S.; Ames, L.; Firon, A.; Green, B.; Cabral, V.; et al. Systematic Phenotyping of a Large-Scale Candida glabrata Deletion Collection Reveals Novel Antifungal Tolerance Genes. Plos Pathog. 2014, 10. [CrossRef]

8. Ellis, D.; Davis, S.; Alexiou, H.; Handke, R.; Bartley, R. Descriptions of medical fungi, mycology unit, women's and children's hospital Adelaide, Australia, 2007.

9. Cebeci Güler, N.; Tosun, I.; Aydin, F. The identification of Meyerozyma guilliermondii from blood cultures and surveillance samples in a university hospital in Northeast Turkey: A ten-year survey. J. Mycol. Med. 2017, 27, 506-513. [CrossRef] 
10. Mügge, C.; Haustein, U.F.; Nenoff, P. Causative agents of onychomycosis-A retrospective study. J. Dtsch. Derm. Ges 2006, 4, 218-228. [CrossRef]

11. Da Cunha, M.M.; Dos Santos, L.P.; Dornelas-Ribeiro, M.; Vermelho, A.B.; Rozental, S. Identification, antifungal susceptibility and scanning electron microscopy of a keratinolytic strain of Rhodotorula mucilaginosa: A primary causative agent of onychomycosis. Fems. Immunol. Med. Microbiol. 2009, 55, 396-403. [CrossRef]

12. Zhou, J.; Chen, M.; Chen, H.; Pan, W.; Liao, W. Rhodotorula minuta as onychomycosis agent in a Chinese patient: First report and literature review. Mycoses 2014, 57, 191-195. [CrossRef] [PubMed]

13. Vimal, V.; Devaki, T. Hepatoprotective effect of allicin on tissue defense system in galactosamine/endotoxin challenged rats. J. Ethnopharmacol. 2004, 90, 151-154. [CrossRef] [PubMed]

14. Corzo-Martínez, M.; Corzo, N.; Villamiel, M. Biological properties of onions and garlic. Trends Food Sci. Tech. 2007, 18, 609-625. [CrossRef]

15. Shi, D.; Lu, G.; Mei, H.; De Hoog, G.S.; Zheng, H.; Liang, G.; Shen, Y.; Li, T.; Liu, W. Onychomycosis due to Chaetomium globosum with yellowish black discoloration and periungual inflammation. Med. Mycol. Case Rep. 2016, 13, 12-16. [CrossRef] [PubMed]

16. Duhard, É. Les paronychies. La Presse Médicale 2014, 43, 1216-1222. [CrossRef] [PubMed]

17. Sinikumpu, S.-P.; Huilaja, L.; Auvinen, J.; Jokelainen, J.; Puukka, K.; Ruokonen, A.; Timonen, M.; Tasanen, K. The Association Between Low Grade Systemic Inflammation and Skin Diseases: A Cross-sectional Survey in the Northern Finland Birth Cohort 1966. Acta Derm. Venereol. 2018, 98, 65-69. [CrossRef]

18. Balea, Ş.S.; Pârvu, A.E.; Pop, N.; Marín, F.Z.; Pârvu, M. Polyphenolic Compounds, Antioxidant, and Cardioprotective Effects of Pomace Extracts from Fetească Neagră Cultivar. Oxid. Med. Cell Longev. 2018, 2018. [CrossRef]

19. Andreicuţ, A.-D.; Parvu, A.E.; Moț, A.C.; Parvu, M.; Fischer-Fodor, E.; Feldrihan, V.; Cătoi, A.F.; Cecan, M.; Irimie, A. Anti-inflammatory and antioxidant effects of Mahonia aquifolium leaves and bark extracts. Farmacia 2018, 66.

20. Gupta, A.K.; Versteeg, S.G.; Shear, N.H. Onychomycosis in the 21st century: An update on diagnosis, epidemiology, and treatment. J. Cutan. Med. Surg. 2017, 21, 525-539. [CrossRef]

21. Altschul, S.F.; Madden, T.L.; Schäffer, A.A.; Zhang, J.; Zhang, Z.; Miller, W.; Lipman, D.J. Gapped BLAST and PSI-BLAST: A new generation of protein database search programs. Nucl. Acids Res. 1997, 25, 3389-3402. [CrossRef]

22. Miron, T.; Shin, I.; Feigenblat, G.; Weiner, L.; Mirelman, D.; Wilchek, M.; Rabinkov, A. A spectrophotometric assay for allicin, alliin, and alliinase (alliin lyase) with a chromogenic thiol: Reaction of 4-mercaptopyridine with thiosulfinates. Anal. Biochem. 2002, 307, 76-83. [CrossRef]

23. Hay, R.J.; Baran, R. Onychomycosis: A proposed revision of the clinical classification. J. Am. Acad. Dermatol. 2011, 65, 1219-1227. [CrossRef] [PubMed]

24. Vlase, L.; Parvu, M.; Parvu, E.; Toiu, A. Chemical constituents of three Allium species from Romania. Molecules 2013, 18, 114-127. [CrossRef] [PubMed]

25. Beato, V.M.; Orgaz, F.; Mansilla, F.; Montaño, A. Changes in phenolic compounds in garlic (Allium sativum L.) owing to the cultivar and location of growth. Plant Foods Hum. Nutr. 2011, 66, 218-223. [CrossRef]

26. Pobłocka-Olech, L.; Głód, D.; Żebrowska, M.E.; Sznitowska, M.; Krauze-Baranowska, M. TLC determination of flavonoids from different cultivars of Allium cepa and Allium ascalonicum. Acta Pharm. 2016, 66, 543-554. [CrossRef] [PubMed]

27. Martins, N.; Barros, L.; Henriques, M.; Silva, S.; Ferreira, I.C.F.R. Activity of phenolic compounds from plant origin against Candida species. Ind. Crop. Prod. 2015, 74, 648-670. [CrossRef]

28. Kanoun, K.; Abbouni, B.; Boudissa, S.; Bouhafs, N.; Seddiki, M. Étude de l'activité des extraits de feuilles de Punica granatum Linn sur Candida albicans et Rhodotorula spp. Phytothérapie 2016, 14, 5-16. [CrossRef]

29. Esposito, T.; Celano, R.; Pane, C.; Piccinelli, A.L.; Sansone, F.; Picerno, P.; Zaccardelli, M.; Aquino, R.P.; Mencherini, T. Chestnut (Castanea sativa Miller.) Burs Extracts and Functional Compounds: UHPLC-UV-HRMS Profiling, Antioxidant Activity, and Inhibitory Effects on Phytopathogenic Fungi. Molecules 2019, 24, 302. [CrossRef]

30. Mot,, A.-C.; Damian, G.; Sarbu, C.; Silaghi-Dumitrescu, R. Redox reactivity in propolis: Direct detection of free radicals in basic medium and interaction with hemoglobin. Redox Rep. 2009, 14, 267-274. [CrossRef] 
31. Moț, A.C.; Pârvu, M.; Pârvu, A.E.; Roşca-Casian, O.; Dina, N.E.; Leopold, N.; Silaghi-Dumitrescu, R.; Mircea, C. Reversible naftifine-induced carotenoid depigmentation in Rhodotorula mucilaginosa (A. Jörg.) FC Harrison causing onychomycosis. Sci. Rep. 2017, 7, 11125. [CrossRef]

32. White, T.J.; Bruns, T.; Lee, S.; Taylor, J. Amplification and direct sequencing of fungal ribosomal RNA genes for phylogenetics. In PCR Protocols: A Guide to Methods and Applications; Academic Press: Cambridge, MA, USA, 1990; Volume 18, pp. 315-322.

33. Perez, G.; Abraira, C.; Oster, J.R.; Lespier, L.; Vaamonde, C.A. The Effect of Dexamethasone on Urinary Acidification. Proc. Soc. Exp. Biol. Med. 1975, 150, 606-611. [CrossRef] [PubMed]

34. Buendía, A.S.A.; González, M.T.; Reyes, O.S.; Arroyo, F.E.G.; García, R.A.; Tapia, E.; Lozada, L.G.S.; Alonso, H.O. Immunomodulatory effects of the nutraceutical garlic derivative allicin in the progression of diabetic nephropathy. Int. J. Mol. Sci. 2018, 19, 1-13.

35. Pârvu, A.E.; Pârvu, M.; Vlase., L.; Miclea., P.; Mot, A.C.; Silaghi-Dumitrescu, R. Anti-inflammatory effects of Allium schoenoprasum L. leaves. J. Physiol. Pharm. 2014, 65, 309-315.

36. Başkol, M.; Dolbun Seçkin, K.; Başkol, G. Advanced oxidation protein products, total thiol levels and total oxidant/antioxidant status in patients with nash. Turk. J. Gastroenterol. 2014, 25, 32-37. [CrossRef]

Sample Availability: Samples of the studied compounds (garlic extract, fungal isolates, and electron microscopic images) are available from the authors.

(C) 2019 by the authors. Licensee MDPI, Basel, Switzerland. This article is an open access article distributed under the terms and conditions of the Creative Commons Attribution (CC BY) license (http://creativecommons.org/licenses/by/4.0/). 